\title{
Clusters in Transition to Circular Economy: Evaluation of Relation
}

\author{
Kristina RAZMINIEN $\dot{E}^{1 *}$, Irina VINOGRADOVA ${ }^{2}$ and Manuela TVARONAVIČIENË $\dot{E}^{3}$
}

Authors' affiliations and addresses:

${ }^{1}$ Department of Economics Engineering, Vilnius

Gediminas Technical University, Vilnius,

Lithuania

e-mail: kristina.razminiene@vilniustech.lt

${ }^{2}$ Department of Information Technologies,

Vilnius Gediminas Technical University, Vilnius,

Lithuania

e-mail: irina.vinogradova@ vilniustech.lt

${ }^{3}$ Department of Business Technologies and Entrepreneurship, Vilnius Gediminas Technical University, Vilnius, Lithuania

e-mail: manuela.tvaronaviciene@ vilniustech.lt

\section{*Correspondence:}

Kristina Razminienè, Department of Economics Engineering, Vilnius Gediminas Technical

University, Vilnius, Lithuania

tel.: +37064695166

e-mail: kristina.razminiene@vilniustech.lt

\section{How to cite this article:}

Razminienè, K., Vinogradova, I. and

Tvaronavičiene, M. (2021). Clusters in Transition to Circular Economy: Evaluation of Relation.

Acta Montanistica Slovaca, Volume 26 (3), 455 465

DOI:

https://doi.org/10.46544/AMS.v26i3.06

\begin{abstract}
Researchers tend to develop cluster studies when the ways of turning to the circular economy are considered. Clusters are viewed as a network where different institutions, enterprises, and research centres are connected to share their knowledge and resources for better results of their performance. Efficient use of resources can be achieved in such networks through involvement in the circular economy. Clusters with their resources and knowledge as contributors in transition to a circular economy are analysed in this paper. The paper aims at literature analysis where clusters and circular economy are overviewed. The links between these two notions are traced, and the relation of clusters in transition to a circular economy is verified through the application of several multicriteria decision-making and mathematics-based information analysis methods. Scientific literature analysis works for the identification of the main concepts and definition of the object. The qualitative and quantitative analysis employs multi-criteria decisionmaking (MCDM) methods (SAW, TOPSIS) and regression analysis. A tool that enables verification of relation between clusters and transition to the circular economy was employed using these methods. The findings suggest that the tool used in the research can be applied when the relation of clusters and transition to a circular economy is being traced. The paper suggests experts' selection through their work experience with clusters and/or circular economy and their evaluation for certain clusters in transition to a circular economy set of criteria. The zero values of some indicators were eliminated by mathematically recalculating the weights so that distortion of the results after the application of MCDM methods is avoided. The results of MCDM methods application in regression analysis show that there is a possible relationship between clusters and transition to a circular economy.
\end{abstract}

\section{Keywords}

Clusters, circular economy, sustainability, resource efficiency, materials processing, raw materials, recycling, reusing, reducing, MCDM. 


\section{Introduction}

The cluster establishment's main aim is to create conditions for increasing the cluster's international competitiveness, encouraging collaboration of its members, and creating more significant value-added in all chains of value creation (Anić, Bačić, \& Aralica, 2018; Kowalski, 2020; Zeibote \& Muravska, 2018). Higher education institutions, research centres are seen as a guarantee of successful scientific research and technological development, enabling the exploitation of the research and technological development potential. Geographical proximity is viewed as one of the most critical factors that allow the collaboration of cluster members (Crass, Rammer, \& Aschhoff, 2019; Juhász \& Lengyel, 2018; Lis, 2020; Xiang \& Huang, 2019). Most of the companies that belong to a cluster are situated in the same city or around it. The cluster members' activities are interrelated, corresponding to the cluster's aim and supplementing each other. The most significant part of the companies in clusters is that they specialise in the same industry, wholesale trade, which allows the production and realisation of products and services to be the cluster's core activity. When companies collaborate, they work together to be more competitive in the market through joint activities. Higher education institutions and research centres provide a scientific approach to technological processes that can be applied in practice (Raychev, Dimitrova, Madzhurova, \& Stoyanova, 2020). Sharing of knowledge and working together helps the companies to boost innovations, increase the quality of production, progress to modern technologies. Other companies supplement the main activity, which helps to strengthen ties and create value-added to cluster activities.

Transition to a circular economy is considered a necessity due to the need for efficient use of resources and waste management (Marino \& Pariso, 2021; Morseletto, 2020; Vatansever, Akarsu, \& Kazançoğlu, 2021). Adopting circular economy business models can not only promote a sustainable economy but also contribute to regional development. The cost of products created using circular business models can be lower than using fossil fuels in terms of damage to the environment. The understanding of such costs should naturally motivate to make changes in all areas. As the world's population grows, so does the demand for raw materials. However, the supply of raw materials is rather limited, and some European Union countries are highly dependent on third countries for their delivery (Eurostat, 2019).

Belonging to a cluster can be viewed as motivation to adapt business models that are beneficial for the member companies. Clusters can encourage companies to adopt circular business models, replace fossil fuel with renewable bio-resources or look back at more sustainable extraction solutions (Baldassarre et al., 2019; Amraoui et al. 2019; Petrenko, Vechkinzova \& Antonov, 2019; Domenech, Bleischwitz, Doranova, Panayotopoulos \& Roman, 2019; Havierniková \& Kordoš, 2019; Mazzoni, 2020; Kudryavtseva, Skhvediani \& Ali, 2020; El Idrissi et al., 2020; Simdiankin et al., 2020; Holzer, Rauter, Fleiß \& Stern, 2021).

The paper aims at literature analysis where clusters and circular economy are overviewed. The links between these two notions are traced, and the relation of clusters in transition to a circular economy is verified through the application of several multi-criteria decision-making and mathematics-based information analysis methods.

Policy and institutional obstacles to competitiveness may be identified through clusters and can be used as practical tools to implement actions to initiate reforms. New partnerships can be evoked to implement policy actions when cluster leaders and various public organisations, like research, innovation, training institutions, industrial and infrastructure development organisations - start working for the same goals (Tang, Plasek, \& Bates, 2018). The provision of specialised infrastructure, country's technology, and knowledge base are areas where cluster growth adds parallel development. Moreover, training and scientific institutions may be established or developed to promote export, set standards and regulations, and other measures. Operational efficiency, more and better jobs, higher exports, better coordination between the public and private sectors in the implementation of legislation are seen as the consequences of clustering. Even more, benefits spread further through the linkages of a cluster (Hilkevics \& Hilkevics, 2017; Monni, Palumbo \& Tvaronavičienè, 2017; Karakayaci, 2018; Žižka et al., 2018; Bublienè et al., 2019; Turkina \& Van Assche, 2018; Xiang \& Huang, 2019; Sarma et al. 2019). If promoted by policymakers, CE's transition can be implemented and fostered by clusters with SMEs through cooperation with different institutions and organisations.

$\mathrm{CE}$ can be a value creation opportunity because it responds with new jobs, new business opportunities, and new markets with possible billions on earnings. It also requires changing mindsets, business models, new products, and services, which is not easy to achieve with the limited time and resources that SMEs usually have. This task can only be made more accessible through partnerships with other companies, researchers, and public authorities.

\section{Literature review}

Many policymakers and researchers acknowledge the value of clusters in introducing advanced technology products and services and promoting regional development. Companies aim to enhance competencies and become stronger actors in the global market. These goals can be achieved by having an advantage from a common and accessible pool of resources, information, and demand for innovation, which means that companies can profit from belonging to a cluster. However, it may be challenging to develop a thriving cluster in many regions or countries. 
The EC in the cluster policy ("Cluster policy | Internal Market, Industry, Entrepreneurship, and SMEs," n.d.) defines clusters as groups of enterprises, usually SMEs, and other institutions that collaborate and support each other, situated in close locations. Clustering is advantageous as it can help deliver innovations, create more jobs, register more international trademarks or patents than SMEs could do without the support of other members. The EC suggests many tools that give guidelines to information bases, mapping tools, and analysis that enable evidence-based policy-making for EU clusters. Cluster organisations have access to training, development, and cluster efficiency improvement through supported partnerships and benchmarking to measure cluster excellence.

Clusters are essential for them to take a significant part of the European industrial landscape. Their principle is a collaboration between enterprises, usually SMEs, and connections within Europe's ecosystem. Clustering supports innovation, internationalisation, and the growth of SMEs. Transnational partnerships are more comfortable to set up when SMEs are a part of a cluster to access global value chains. Clusters can be estimated as enablers of digital and carbon-neutral transformation.

Clusters are viewed as a powerful economic development tool for they can support innovation and industry. They can be involved in smart specialisation communication and CE, and new cluster initiatives can be launched. However, new cluster initiatives need to focus on implementing clear visions of regional government and new markets.

Authors present different approaches to cluster typologies. Turkina and Van Assche (2018) introduce horizontal (by specialisation) and vertical (complementary) types of clusters. This simplistic approach gives characteristics of a cluster rather than its typology. Cluster formation presents the level of specialisation and complementariness sought within an area that closely conforms to efficiency and effectiveness. Zelbst, Frazier, and Sower (2010) have done research where three cluster typologies were identified. The discussion on the typologies of Porter (2003) and Markusen (1996) is presented in their study.

The circular economy (CE) was declared a priority in the development of the European Union (EU) by encouraging job creation, growth, and investment together with a carbon-neutral, resource-efficient, and competitive economy (European Commission, 2019). The linear economy model with its take-make-use-dispose principle is being changed by $\mathrm{CE}$, which declares that alternative business models should be adopted, focusing on resource efficiency, doing less damage to the environment, the economy, and society. Unlike the linear economy, CE follows a 3R principle - reduce-reuse-recycle - when considering the lifecycle of resources. Transition to a $\mathrm{CE}$ helps in job creation, opens up new business opportunities, and gives rise to new business models, and valueadded creation develops new markets inside and outside the EU. Despite that, the transition to CE is relatively slow, leaving huge room for improvement.

Resource efficiency is becoming more critical for SMEs, and they start looking at circular business models to turn their waste into assets (Mannina et al., 2021; Turkina \& Van Assche, 2018). Clusters and cluster organisations can play a considerable role in SMEs becoming more resource-efficient. The necessity of cluster performance evaluation is captured on a national level to identify weaknesses and strengths for further developing and improving a cluster. Clusters may foster the transition to CE to a greater extent, for SMEs can usually be unable to implicate innovative solutions on their own (Tedesco \& Montacchini, 2020). Hence, the need to develop a clusters' performance measurement methodology that allows assessment of clusters' contribution to the transition to $\mathrm{CE}$ is identified.

\section{Material and Methods}

The study was performed by applying multi-criteria decision-making (MCDM) methods for a set of indicators that are selected to be used in clusters' performance and transition to CE evaluation are expressed in different units (Hashemi, Dowlatshahi, \& Nezamabadi-pour, 2020; Shen, Wang, \& Wang, 2019). MCDM methods are often used when the alternatives that could be depicted are considered infinite. The indicators of cluster performance are based on the European Secretariat for Cluster Analysis ("The European Secretariat for Cluster Analysis (ESCA) — ESCA," n.d.), which suggests benchmarking and labelling clusters according to their quality. The other group of indicators is based on European Commission (EC) planned actions in monitoring the process of transfer to CE (European Commission, 2015). The total number of 35 indicators - 25 indicating cluster performance and 10 dedicated to measuring transition to $\mathrm{CE}$ - was further referred for experts. Seven experts were chosen regarding their experience in these two fields (Table 1).

\begin{tabular}{ccccc}
\multicolumn{2}{c}{ Tab. } & The selection criteria of experts by education, position, experience in clusters and circular economy in years (Composed by authors) \\
\hline No & Education & Position & Experience in clusters & Experience in the circular economy \\
\hline 1 & PhD & Head of Department & 15 & 10 \\
2 & MSc & Director & 13 & 4 \\
3 & MSc & Director & 9 & 3 \\
4 & MSc & Director & 3 & 0 \\
5 & $\mathrm{MSc}$ & Director & 2 & 8 \\
6 & $\mathrm{BSc}$ & Director & 3 & 7 \\
7 & $\mathrm{PhD}$ & Coordinator & 1 \\
\hline
\end{tabular}


The education and position of the selected experts vary from bachelor's and master's to doctoral degrees and from coordinator to the director and head of the department irrespectively to the degree of education. The experts belong to governmental, higher education institutions, or non-profit organisations. These criteria are applied as experts who work in listed institutions are familiar with the legislation and can give recommendations on the further development of the clusters in transition to CE. They also have experience in at least one field of study, which varies from two to fifteen years in clusters and none to ten years in CE. All of the experts are familiar with clusters.

The experts were asked to determine whether the indicators are appropriate for further treatment and then give weights for each indicator in five groups totalling 100 per cent. The first element of cluster performance was subdivided into smaller categories as 25 indicators are too many to process as one group. The subdivision resulted in four groups, including six to seven indicators and added one more stage in the evaluation process as these four groups were meant to be counted as part of a unit as well. The CE element includes ten indicators which is an appropriate number for expert evaluation. All in all, six groups of indicators were composed in a hierarchical structure so that each level in the hierarchy has an appropriate number of indicators to be evaluated by experts.

The experts' evaluations were used to determine the weights of every indicator so that SAW and TOPSIS methods could be applied. SAW - Simple Additive Weighting - method is often used in decision making as it is easy to apply and gives results in numerical values (Sadabadi, Hadi-Vencheh, Jamshidi, \& Jalali, 2021; Stevi'cstevi'c, Durmi'cdurmi'c, Gaji'cgaji'c, Pamučar, \& Puška, 2019; Wang, 2019). These values can be distributed widely, so authors usually suggest using several methods (Meshram, Alvandi, Meshram, Kahya, \& Fadhil AlQuraishi, 2020; Seyedmohammadi, Sarmadian, Jafarzadeh, Ghorbani, \& Shahbazi, 2018) to confirm the reliability of a tool. Another MCDM method TOPSIS - the Technique of Order of Preference by Similarity to Ideal Solution - is used as the results are obtained on a scale from 0 to 1 and can be easily converted into percentage values (Bid \& Siddique, 2019; Youssef, 2020). Both methods are used together as they complement the tool rather than contradict each other.

The regression analysis is used in the final stage of the study. This method is chosen as it is a mathematical method to quantify the strength of the relationship between two quantitative variables (Deerfield, 2019; Dirican, 2019). Hence, the degree of correlation between cluster performance and transition to a circular economy is identified.

\section{Results}

Companies today experience many challenges and meet the opportunities because of globalisation and the continuing technological revolution. Smaller countries lack the domestic market necessary for companies to grow, as well as have weaker infrastructures and limited support for industrial companies. The development of regional clusters has been promoted in many countries, where companies can build their competencies and gain advantages in the face of the world's leading companies by sharing resources, innovative capabilities, and knowledge following the recognition of insufficiencies and potential weaknesses.

The indicators that allow the evaluation of cluster performance in transition to CE were developed according to scientific literature analysis and other international and national observation agencies. The system of indicators was formed by including the most informative indicators. Cluster performance evaluation includes 25 indicators separated into four components: intercommunication with six indicators, marketing activities with six indicators, human resources with seven indicators, and financial resources with six indicators. Transition to CE evaluation includes ten indicators that are no further sub-divided. Data were collected from several sources: Sodra, EPA, Klaster.lt, and clusters' coordinators.

The evaluation started with experts' evaluations. Seven experts were asked to give percentage values to each criterion in every group so that the total percentage in one group was summed up to 100 per cent. Such allocation allowed to verify the validity of selected criteria. The percentage values of experts' evaluations were turned into ranks. The highest-ranking - rank 1 - was assigned to the most important indicator, and the lowest ranking (rank 6 , rank 7 , or rank 10 , depending on the number of indicators) was given to the least important one. Then, the concordance coefficient $W$ (equation 1 ) and the mean of criteria $\chi^{2}$ (equation 2 ) are determined.

$$
\begin{aligned}
& W=\frac{12 S}{T^{2}\left(m^{2}-m\right)-T \sum_{t=1}^{T} R_{t}}, \\
& \chi^{2}=\frac{12 S}{T m(m+1)-\frac{1}{m-1} \sum_{t=1}^{T} R_{t}},
\end{aligned}
$$

here, $m$ - the number of compared objects or elements;

$T-$ the number of experts,

$S$ - deviation of the means of the sum of squares of the experts' assessment from the overall average (equation $3)$; 
$R_{t}-$ associated ranks indicator (equation 4$)$

$$
S=\sum_{i=1}^{m}\left(s_{i}-s_{a v}\right)^{2}
$$

when $s_{i}$ is the sum of the ranks of each comparator $i, s_{a v}$ is the total average.

$$
R_{t}=\sum_{g=1}^{G_{t}}\left(l_{g}^{3}-l_{g}\right)
$$

here $G_{t}$ is the number of the $t$-th expert level ranks.

The value of concordance coefficient $W$ shows if the assessment of experts agrees. The values can vary between 0 and 1 when $W$ value close to 0 shows inconsistent assessment and a value close to 1 shows that the assessment agrees.

With the significance level $\alpha$ (practice $\alpha$ value is usually 0,05 or 0,01 ) and the degree of freedom $m-1$ we find the critical value $\chi_{k r}^{2}$ from the table of $\chi^{2}$ distribution. The $\chi^{2}$ value (equation 2) shows the consistency of experts' assessment if it is higher than $\chi_{k r}^{2}$.

The concordance coefficient $W$ (equation 1) and the criterion $\chi^{2}$ (equation 2) were calculated for each decision stage to check the consistency of experts' assessment. The values of the table $\chi_{k r}^{2}$ depend on the significance level $\alpha$ and the degree of freedom $m-1$.

The indicators were distributed according to their importance. Table 2 shows the distribution of indicators of the first component as evaluated by experts and then ranked.

Tab. 2. Distribution of indicators of the first component according to experts' assessment (Composed by the authors)

\begin{tabular}{ccccccc}
\hline Indicator & C5 & C1 & C2 & C6 & C3 & C4 \\
\hline Rank sum & 12 & 16.5 & 18 & 29.5 & 31 & 40 \\
\hline
\end{tabular}

We need to determine the concordance coefficient when the same rank value is prescribed in the evaluation of one expert. When equation (1) is applied: $S=570 ; m=6 ; T=7$. Associated ranks indicators get the following values: $R_{1}=0.5 ; R_{2}=0.5 ; R_{3}=0.5 ; R_{4}=1 ; R_{5}=5.5 ; R_{6}=1 ; R_{7}=1$. The sum of associated ranks indicators equals 10:

$$
\sum_{t=1}^{T} R_{t}=10
$$

The concordance coefficient $W=0.72$ shows the high consistency of experts' evaluations. Coefficient $\chi^{2}=$ 25.33, which is more than $\chi_{k r(\alpha=0.05, m-1=5)}^{2}=11.07$; and confirm the previous decision.

The second group of indicators was evaluated and ranked likewise, given in Table 3.

Tab. 3. Distribution of indicators of the second component according to experts' assessment (Composed by the authors)

\begin{tabular}{ccccccc}
\hline Indicator & C11 & C10 & C7 & C9 & C12 & C8 \\
\hline Rank sum & 12 & 12.5 & 26 & 27.5 & 30.5 & 38.5 \\
\hline
\end{tabular}

When equation (1) is applied: $S=543.5, m=6, T=7$. Associated ranks indicators get the following values: $R_{7}=0.5 ; R_{8}=0.5 ; R_{9}=0.5 ; R_{10}=0.5 ; R_{11}=1 ; R_{12}=0.5 ; R_{13}=0.5$. The sum of associated ranks indicators equals 3.5:

$$
\sum_{t=1}^{T} R_{t}=3.5
$$

The concordance coefficient $W=0.65$ shows the average consistency of experts' evaluations. Coefficient $\chi^{2}=22.84$, which is more than $\chi_{k r(\alpha=0.05, m-1=5)}^{2}=11.07$; and the results can be used in further calculations.

The third group of indicators was evaluated, and the sums of ranks are given in Table 4.

Tab. 4. Distribution of indicators of the third component according to experts' assessment (Composed by the authors)

\begin{tabular}{cccccccc} 
Indicator & $\mathrm{C} 18$ & $\mathrm{C} 15$ & $\mathrm{C} 17$ & $\mathrm{C} 16$ & $\mathrm{C} 13$ & $\mathrm{C} 14$ & C19 \\
\hline Rank sum & 16.5 & 17 & 21 & 30.5 & 34 & 34 & 43 \\
\hline
\end{tabular}

When equation (1) is applied: $S=605.5, m=7, T=7$. Associated ranks indicators get the following values: $R_{13}=1.5 ; R_{14}=2.5 ; R_{15}=2.5 ; R_{16}=2 ; R_{17}=10 ; R_{18}=7, R_{19}=5$. The sum of associated ranks indicators equals 30.5 :

$$
\sum_{t=1}^{T} R_{t}=30.5
$$


The concordance coefficient $W=0.52$ shows the average consistency of experts' evaluations. Coefficient $\chi^{2}=21.95$, which is more than $\chi_{k r(\alpha=0.05, m-1=5)}^{2}=12.59$; and the results can be used in further calculations.

The fourth group of indicators gets such results shown in Table 5.

Tab. 5. Distribution of indicators of the fourth component according to experts' assessment (Composed by the authors)

\begin{tabular}{ccccccc}
\hline Indicator & $\mathrm{C} 25$ & $\mathrm{C} 21$ & $\mathrm{C} 22$ & $\mathrm{C} 20$ & $\mathrm{C} 23$ & $\mathrm{C} 24$ \\
\hline Rank sum & 14.5 & 16 & 20.5 & 25 & 35.5 & 35.5 \\
\hline
\end{tabular}

When equation (1) is applied: $S=430.5, m=6, T=7$. Associated ranks indicators get the following values: $R_{20}=5.5 ; R_{21}=1 ; R_{22}=1 ; R_{23}=1 ; R_{24}=5.5 ; R_{25}=5.5$. The sum of associated ranks indicators equals 30.5:

$$
\sum_{t=1}^{T} R_{t}=19.5
$$

The concordance coefficient $W=0.6$ shows the average consistency of experts' evaluations. Coefficient $\chi^{2}=11.07$, which is more than $\chi_{k r(\alpha=0.05, m-1=5)}^{2}=21.1$; and the results can be used in further calculations.

Further assessment requires to rank previous four groups of indicators as one component for cluster performance evaluation. The given ranks are provided in Table 6.

Tab. 6. Distribution of indicators of the cluster performance evaluation component according to experts' assessment (Composed by the

\begin{tabular}{ccccc} 
& \multicolumn{4}{c}{ authors) } \\
\hline Indicator & CP1 & CP2 & CP3 & CP4 \\
\hline Rank sum & 8 & 18.5 & 19.5 & 24 \\
\hline
\end{tabular}

When equation (1) is applied: $S=137.5, m=4, T=7$. Associated ranks indicators get the following values: $R_{26}=0.5 ; R_{27}=0.5 ; R_{28}=0.5 ; R_{29}=2$. The sum of associated ranks indicators equals 3.5 :

$$
\sum_{t=1}^{T} R_{t}=3.5
$$

The concordance coefficient $W=0.62$ shows the average consistency of experts' evaluations. Coefficient $\chi^{2}=13.1$, which is more than $\chi_{k r(\alpha=0.05, m-1=5)}^{2}=7.81$; and the results can be used in further calculations.

The final component consists of CE evaluation indicators, and the ranks are given in Table 7.

Tab. 7. Distribution of indicators of the circular economy performance evaluation component according to experts' assessment (Composed

\begin{tabular}{lllllllllll}
\hline Indicator & CE1 & CE2 & CE3 & CE4 & CE5 & CE6 & CE7 & CE8 & CE9 & CE10 \\
\hline Rank sum & 11.5 & 20.5 & 20.5 & 47.5 & 47.5 & 47.5 & 47.5 & 47.5 & 47.5 & 47.5 \\
\hline
\end{tabular}

When equation (1) is applied: $S=1944, m=10, T=7$. Associated ranks indicators get the following values: $R_{30}=82.5 ; R_{31}=28.5 ; R_{32}=28.5 ; R_{33}=28.5 ; R_{34}=28.5 ; R_{35}=28.5 ; R_{36}=28.5$. The sum of associated ranks indicators equals 253.5 :

$$
\sum_{t=1}^{T} R_{t}=253.5
$$

The concordance coefficient $W=0.86$ shows the high consistency of experts' evaluations. Coefficient $\chi^{2}=$ 64 , which is more than $\chi_{k r(\alpha=0.05, m-1=5)}^{2}=16.92$; and the results can be used in further calculations.

The calculated weights allow the application of MCDM methods to process the results. As the weights were known, further actions were taken. MCDM methods can be applied when multi-dimensional measures need to be included in the calculations. This was the case as both cluster performance and transition to CE components are composed of indicators that are expressed in various measures. Cluster performance evaluation indicators have measures of scale (1-8), per cent, number, or currency (Table 8). In the case of cluster performance, all the indicators have maximising variation nature. 
Tab. 8. The measures, variation nature, and weights of cluster performance indicators (Composed by the authors)

\begin{tabular}{|c|c|c|c|}
\hline No & Measure & Variation nature & Weight \\
\hline $\mathrm{C} 1$ & scale: $1-8$ & $\max$ & 7.200 \\
\hline $\mathrm{C} 2$ & scale: $1-8$ & $\max$ & 6.720 \\
\hline $\mathrm{C} 3$ & scale: $1-8$ & $\max$ & 4.320 \\
\hline $\mathrm{C} 4$ & scale: $1-8$ & $\max$ & 2.640 \\
\hline C5 & scale: $1-8$ & $\max$ & 7.920 \\
\hline C6 & scale: $1-8$ & $\max$ & 4.800 \\
\hline $\mathrm{C} 7$ & scale: $1-8$ & $\max$ & 2.343 \\
\hline $\mathrm{C} 8$ & scale: $1-8$ & $\max$ & 2.109 \\
\hline C9 & scale: $1-8$ & $\max$ & 2.694 \\
\hline $\mathrm{C} 10$ & scale: $1-8$ & $\max$ & 3.397 \\
\hline $\mathrm{C} 11$ & scale: $1-8$ & $\max$ & 3.631 \\
\hline $\mathrm{C} 12$ & scale: $1-8$ & $\max$ & 2.226 \\
\hline $\mathrm{C} 13$ & per cent & $\max$ & 3.017 \\
\hline $\mathrm{C} 14$ & number & $\max$ & 2.828 \\
\hline $\mathrm{C} 15$ & currency & $\max$ & 5.092 \\
\hline $\mathrm{C} 16$ & number & $\max$ & 3.206 \\
\hline $\mathrm{C} 17$ & number & $\max$ & 4.526 \\
\hline $\mathrm{C} 18$ & number & $\max$ & 5.846 \\
\hline C19 & number & $\max$ & 1.886 \\
\hline $\mathrm{C} 20$ & number & $\max$ & 3.708 \\
\hline $\mathrm{C} 21$ & number & $\max$ & 4.720 \\
\hline $\mathrm{C} 22$ & currency & $\max$ & 4.214 \\
\hline $\mathrm{C} 23$ & number & $\max$ & 2.697 \\
\hline $\mathrm{C} 24$ & number & $\max$ & 2.697 \\
\hline $\mathrm{C} 25$ & currency & $\max$ & 5.563 \\
\hline
\end{tabular}

Transition to CE indicators is measured in tonnes or per cent (Table 9). The varied nature of CE indicators can be minimising or maximising.

Tab. 9. The measures, variation nature, and weights of circular economy indicators (Composed by the authors)

\begin{tabular}{|c|c|c|c|}
\hline No & Measure & Variation nature & Weight \\
\hline CE1 & tonnes & $\min$ & 5.714 \\
\hline CE2 & tonnes & $\min$ & 5.714 \\
\hline CE3 & tonnes & $\min$ & 5.714 \\
\hline CE4 & tonnes & $\min$ & 5.714 \\
\hline CE5 & tonnes & $\min$ & 5.714 \\
\hline CE6 & tonnes & $\min$ & 5.714 \\
\hline CE7 & tonnes & $\min$ & 5.714 \\
\hline CE8 & percent & $\max$ & 15 \\
\hline CE9 & percent & $\max$ & 15 \\
\hline CE10 & percent & $\max$ & 30 \\
\hline
\end{tabular}

The tables show that cluster performance and circular economy indicators are expressed in scale (1-8), number, currency (Euros), tonnes, or per cent. The comparison among criteria can be performed after the normalisation of the matrix is applied to transform differently measured criteria into non-dimensional.

In this study, data was collected from open access, limited access, and confidential data sources. Some of the indicators received zero values. When MCDM methods are applied, criteria that could result in zeros should be eliminated at the initial stage of tool formation as zeros can distort the final result. Here, zeros may have resulted in the distortion of the final results, so another solution was applied. Calculations of the results were made in a non-traditional mathematically correct way by recalculating weights for every cluster regarding the collected data. 
When the SAW method was applied, the calculations resulted in values given in Table 10 of six clusters. The results are scattered in a wide range of numerical values. The lowest result is 0.31429 and the highest 35.41901 in cluster's performance, while the lowest is 0.001123 and the highest is 49.21653 in transition to CE.

Tab. 10. SAW results when cluster's performance and transition to a circular economy are calculated for clusters A1, A2, A3, A4, A5, A6 (Composed by the authors)

\begin{tabular}{ccc}
\hline SAW & Cluster's performance & Transition to CE \\
\hline A1 & 0.377751 & 0.036627 \\
A2 & 35.41901 & 37.40862 \\
A3 & 0.344913 & 34.99497 \\
A4 & 0.344608 & 0.295731 \\
A5 & 0.355406 & 0.001123 \\
A6 & 0.31429 & 49.21653 \\
\hline
\end{tabular}

The results when TOPSIS was applied are given in Table 11 of six clusters. The values range from zero to one when the TOPSIS method is applied. The results vary from 0.4250865 to 0.560619 in cluster's performance and from 0 to 0.9986121 when transition to CE is evaluated.

Tab. 11. TOPSIS results when cluster's performance and transition to a circular economy are calculated for clusters A1, A2, A3, A4, A5, A6

\begin{tabular}{ccc} 
& (Composed by the authors) & \\
\hline TOPSIS & Cluster's performance & Transition to CE \\
A1 & 0.560619 & 0.970508 \\
A2 & 0.4736671 & 0.4104166 \\
A3 & 0.5166439 & 0.8313364 \\
A4 & 0.4709938 & 0.9986121 \\
A5 & 0.4601486 & 0 \\
A6 & 0.4250865 & 0.3235629 \\
\hline
\end{tabular}

The results when SAW and TOPSIS methods are applied do not coincide as a leader cluster is not clear when the results are compared because the nature of the methods differs. Further research with a larger scale of the target should be involved to examine which method is more reliable when cluster's performance or transition to CE needs to be evaluated. The final step in the study takes SAW and TOPSIS results separately to observe if the cluster's performance and transition to CE correlate.

The correlation is always between -1 and +1 , and its scale is independent of the scale of the variables themselves, allowing us to compare variables measured in different ways. Correlation is a standardised measure between two variables. The correlation coefficient, in a broad sense, shows some relationship between the selected factors.

The coefficient of determination $\boldsymbol{R}^{2}$ equals 0.507973 when the results of SAW analysis were evaluated and 0.6589917 when the results of TOPSIS analysis were evaluated, which shows a moderate positive relationship in both cases. When the coefficient of determination $\boldsymbol{R}^{2}$ is considered, the conclusions can be drawn that there is primary causation between cluster's performance and transition to $\mathrm{CE}$.

\section{Conclusions}

Clusters as a subject show their importance through case analyses in various contexts globally and locally. One of the most important advantages for companies belonging to a cluster is very often viewed as competitiveness which is gained through knowledge transfer, innovations, value chains. Clusters are naturally formed by geographical proximity and contribute to regional development through innovations, R\&D, start-ups, and other activities. Companies alone usually lack knowledge and resources when new business models need to be implemented. Clusters can be promoters of CE for their members through knowledge bases and resources.

The original tool that enables the evaluation of cluster performance in transition to CE is applied in the case of six clusters. The tool is implemented in several stages. Experts approved previously selected indicators, and the weights were determined. The consistency of experts was verified by measuring the concordance coefficient. The prepared structure of indicators with determined weights allowed MCDM methods to be applied. The last step taken to complete the study was the application of regression analysis.

The study provides guidelines of experts' selection according to their education, position, experience in clusters, and circular economy in years. The experts' positions ensure that they are fully aware of regulations and can make valuable observations or suggestions regarding clusters' or CE policy. Detailed evaluations of experts are given in the study, with weights ascribed to cluster performance and transition to CE indicators. Two MCDM methods are applied for the calculation of the results that are used to track if there is a relationship between cluster performance and transition to CE. The coefficient of determination $\boldsymbol{R}^{2}$ shows a moderate positive relationship when both SAW and TOPSIS results are applied. The study shows that cluster performance can cause a transition to CE. 
Further research could include a wider range of data for more detailed analysis. More clusters should be involved in the submission of data which would result in an extensive data period.

\section{References}

Amraoui, B., Ouhajjou, A., Monni, S., El Amrani El Idrissi, N., \& Tvaronavičienė, M. (2019). Performance of clusters in Morocco in the shifting economic and industrial reforms. Insights into Regional Development, 1(3), 227-243. https://doi.org/10.9770/ird.2019.1.3(4)

Anić, I. D., Bačić, K., \& Aralica, Z. (2018). The competitiveness clusters in Croatia. Ekonomski Pregled, 69(5), 571-593. https://doi.org/10.32910/ep.69.5.5

Baldassarre, B., Schepers, M., Bocken, N., Cuppen, E., Korevaar, G., \& Calabretta, G. (2019). Industrial Symbiosis: towards a design process for eco-industrial clusters by integrating Circular Economy and Industrial Ecology perspectives. Journal of Cleaner Production, 216, 446-460. https://doi.org/10.1016/j.jclepro.2019.01.091

Bid, S., \& Siddique, G. (2019). Human risk assessment of Panchet Dam in India using TOPSIS and WASPAS Multi-Criteria Decision-Making (MCDM) methods. Heliyon, 5(6), e01956. https://doi.org/10.1016/j.heliyon.2019.e01956

Bublienè, R., Vinogradova, I., Tvaronavičienè, M. \& Monni, S. (2019). Legal form determination for the development of clusters' activities. Insights into Regional Development, 1(3), 244-258. https://doi.org/10.9770/ird.2019.1.3(5)

Cluster policy | Internal Market, Industry, Entrepreneurship and SMEs. (n.d.). Retrieved December 30, 2019, from https://ec.europa.eu/growth/industry/policy/cluster_en

Crass, D., Rammer, C., \& Aschhoff, B. (2019). Geographical clustering and the effectiveness of public innovation programs. Journal of Technology Transfer, 44(6), 1784-1815. https://doi.org/10.1007/s10961-017-9584-X

Deerfield, A. (2019). Quantile regression analysis of cooperative learning effects. International Review of Economics Education, 30, 100132. https://doi.org/10.1016/j.iree.2018.04.001

Dirican, S. (2019). A preliminary correlation and regression study on drinking water quality of Suşehri district in Turkey. Romanian Biotechnological Letters, 24(2), 201-207. https://doi.org/10.25083/rbl/24.2/201.207

Domenech, T., Bleischwitz, R., Doranova, A., Panayotopoulos, D., \& Roman, L. (2019). Mapping Industrial Symbiosis Development in Europe_typologies of networks, characteristics, performance and contribution to the Circular Economy. Resources, Conservation and Recycling, 141, 76-98. https://doi.org/10.1016/j.resconrec.2018.09.016

El Idrissi, N. E. A., Ilham Zerrouk, I., Zirari, N., \& Monni, S. 2020. Comparative study between two innovative clusters in Morocco and Italy. Insights into Regional Development, 2(1), 400-417. http://doi.org/10.9770/IRD.2020.2.1(1)

European Commission. (2015). Circular Economy Action Plan. 27.

European Commission. (2019). Report from the commission to the European Parliament, the Council, the European Economic and Social Committee and the Committee of the Regions. Retrieved from https://ec.europa.eu/eurostat/tgm/table.do?tab=table\&init=1\&language=en\&pcode=cei_srm030\&plugin= 1

Eurostat. (2019). Statistics | Eurostat. Retrieved March 8, 2021, from Eurostat website: https://ec.europa.eu/eurostat/databrowser/view/cei_srm030/default/table?lang=en

Hashemi, A., Dowlatshahi, M. B., \& Nezamabadi-pour, H. (2020). MFS-MCDM: Multi-label feature selection using multi-criteria decision making. Knowledge-Based Systems, 206, 106365. https://doi.org/10.1016/J.KNOSYS.2020.106365

Havierniková, K. \& Kordoš, M. 2019. Selected risks perceived by SMEs related to sustainable entrepreneurship in case of engagement into cluster cooperation. Entrepreneurship and Sustainability Issues, 6(4), 16801693. http://doi.org/10.9770/jesi.2019.6.4(9)

Hilkevics, S., \& Hilkevics, A. (2017). The comparative analysis of technology transfer models. Entrepreneurship and Sustainability Issues, 4(4), 540-558. http://doi.org/10.9770/jesi.2017.4.4(11)

Holzer, D., Rauter, R., Fleiß, E., \& Stern, T. (2021). Mind the gap: Towards a systematic circular economy encouragement of small and medium-sized companies. Journal of Cleaner Production, 298. https://doi.org/10.1016/J.JCLEPRO.2021.126696

Juhász, S., \& Lengyel, B. (2018). Creation and persistence of ties in cluster knowledge networks. Journal of Economic Geography, 18(6), 1203-1226. https://doi.org/10.1093/JEG/LBX039

Karakayaci, O. (2018). Social Networks and Innovation in Industrial Clusters: A Study in case of Turkish Industrial Clusters. MEGARON / Yıldız Technical University, Faculty of Architecture E-Journal, 13(3), 374-394. https://doi.org/10.5505/megaron.2018.91489

Kowalski, A. M. (2020). Towards an asian model of clusters and cluster policy: The super cluster strategy. Journal of Competitiveness, 12(4), 74-90. https://doi.org/10.7441/joc.2020.04.05 
Kudryavtseva, T., Skhvediani, A., \& Ali, M. 2020. Modeling cluster development using programming methods: case of Russian Arctic regions. Entrepreneurship and Sustainability Issues, 8(1), 150-176. http://doi.org/10.9770/jesi.2020.8.1(10)

Lis, A. M. (2020). Development of proximity in cluster organizations. Entrepreneurship and Sustainability Issues, 8(2), 116-132. https://doi.org/10.9770/JESI.2020.8.2(7)

Mannina, G., Badalucco, L., Barbara, L., Cosenza, A., Di Trapani, D., Gallo, G., ... Helness, H. (2021). Enhancing a transition to a circular economy in the water sector: The eu project wider uptake. Water 13(7), 946. https://doi.org/10.3390/w13070946

Marino, A., \& Pariso, P. (2021). The transition towards to the circular economy: European SMEs' trajectories. Entrepreneurship and Sustainability Issues, 8(4), 431-455. https://doi.org/10.9770/JESI.2021.8.4(26)

Markusen, A. (1996). Sticky places in slippery space: A typology of industrial districts. Economic Geography, 72(3), 293-313. https://doi.org/10.2307/144402

Mazzoni, F. (2020). Circular economy and eco-innovation in Italian industrial clusters. Best practices from Prato textile cluster. Insights into Regional Development, 2(3), 661-676. https://doi.org/10.9770/IRD.2020.2.3(4)

Meshram, S. G., Alvandi, E., Meshram, C., Kahya, E., \& Fadhil Al-Quraishi, A. M. (2020). Application of SAW and TOPSIS in Prioritizing Watersheds. Water Resources Management, 34(2), 715-732. https://doi.org/10.1007/s11269-019-02470-x

Monni, S., Palumbo, \& Tvaronavičienè, M. (2017). Cluster performance: an attempt to evaluate the Lithuanian case. Entrepreneurship and Sustainability Issues, 5(1), 43-57. http://doi.org/10.9770/jesi.2017.5.1(4)

Morseletto, P. (2020). Targets for a circular economy. Resources, Conservation and Recycling, 153, 104553. https://doi.org/10.1016/j.resconrec.2019.104553

Petrenko, Y., Vechkinzova, E., \& Antonov, V. (2019). Transition from the industrial clusters to the smart specialization of the regions in Kazakhstan. Insights into Regional Development, 1(2), 118128. https://doi.org/10.9770/ird.2019.1.2(3)

Porter, M. E. (2003). The economic performance of regions. Regional Studies, 37(6-7), 545-546. https://doi.org/10.1080/0034340032000108688

Raychev, S., Dimitrova, G., Madzhurova, B., \& Stoyanova, D. (2020). Innovations as a Factor for Economic Growth and Labor Market Development. Marketing and Management of Innovations, (3), $22-31$. https://doi.org/10.21272/mmi.2020.3-02

Sadabadi, S. A., Hadi-Vencheh, A., Jamshidi, A., \& Jalali, M. (2021). A linear programming technique to solve fuzzy multiple criteria decision making problems with an application. RAIRO - Operations Research, 55(1), 83-97. https://doi.org/10.1051/ro/2020116

Sarma, U., Karnitis, G., Zuters, J., \& Karnitis, E. (2019). District heating networks: enhancement of the efficiency. Insights into Regional Development, 1(3), 200-213. https://doi.org/10.9770/ird.2019.1.3(2)

Simdiankin, A.A., Probin, P.S., Gerasimova, L.N., Kevorkova, Zh. A., Dikikh, V.A., \& Nurmanov, A.O. (2020). Method for evaluating the possibility of cluster forming. Entrepreneurship and Sustainability Issues, 7(4), 3145-3157. https://doi.org/10.9770/jesi.2020.7.4(37)

Seyedmohammadi, J., Sarmadian, F., Jafarzadeh, A. A., Ghorbani, M. A., \& Shahbazi, F. (2018). Application of SAW, TOPSIS and fuzzy TOPSIS models in cultivation priority planning for maize, rapeseed and soybean crops. Geoderma, 310, 178-190. https://doi.org/10.1016/j.geoderma.2017.09.012

Shen, K. wen, Wang, X. kang, \& Wang, J. qiang. (2019). Multi-criteria decision-making method based on Smallest Enclosing Circle in incompletely reliable information environment. Computers and Industrial Engineering, 130, 1-13. https://doi.org/10.1016/j.cie.2019.02.011

Stevi'cstevi'c, Ž., Durmi'cdurmi'c, E., Gaji'cgaji'c, M., Pamučar, D., \& Puška, A. (2019). A Novel Multi-Criteria Decision-Making Model: Interval Rough SAW Method for Sustainable Supplier Selection. https://doi.org/10.3390/info10100292

Tang, C., Plasek, J. M., \& Bates, D. W. (2018, November 22). Rethinking data sharing at the dawn of a health data economy: A viewpoint. Journal of Medical Internet Research, 20(11), e11519. https://doi.org/10.2196/11519

Tedesco, S., \& Montacchini, E. (2020). From textile waste to resource: a methodological approach of research and experimentation. Sustainability, 12(24), 1-12. https://doi.org/10.3390/su122410667

The European Secretariat for Cluster Analysis (ESCA) - ESCA. (n.d.). Retrieved June 5, 2021, from https://www.cluster-analysis.org/

Turkina, E., \& Van Assche, A. (2018). Global connectedness and local innovation in industrial clusters. Journal of International Business Studies, 49(6), 706-728. https://doi.org/10.1057/s41267-018-0153-9

Vatansever, K., Akarsu, H., \& Kazançoğlu, Y. (2021). Evaluation of Transition Barriers to Circular Economy: A Case from the Tourism Industry. International Journal of Mathematical, Engineering and Management Sciences, 6(3), 824-846. https://doi.org/10.33889/IJMEMS.2021.6.3.049

Wang, Y. J. (2019). Interval-valued fuzzy multi-criteria decision-making based on simple additive weighting and relative preference relation. Information Sciences, 503, 319-335. https://doi.org/10.1016/j.ins.2019.07.012 
Xiang, X., \& Huang, W. C. (2019). Does distance affect the role of nonlocal subsidiaries on cluster firms' innovation? An empirical investigation on Chinese biotechnology cluster firms. Sustainability, 11(23), 6725. https://doi.org/10.3390/su11236725

Youssef, A. E. (2020). An integrated MCDM approach for cloud service selection based on TOPSIS and BWM. IEEE Access, 8, 71851-71865. https://doi.org/10.1109/ACCESS.2020.2987111

Zeibote, Z., \& Muravska, T. (2018). Promoting the regional competitiveness through clusters' approach: case of the Latvian information technology cluster. European Integration Studies, 0(12), 77-91. https://doi.org/10.5755/j01.eis.0.12.20846

Zelbst, P. J., Frazier, G. V., \& Sower, V. E. (2010). A cluster concentration typology for making location decisions. Industrial Management and Data Systems, 110(6), 883-907. https://doi.org/10.1108/02635571011055108

Žižka, M., Hovorková Valentová, V., Pelloneová, N., \& Štichhauerová, E. (2018). The effect of clusters on the innovation performance of enterprises: traditional vs new industries. Entrepreneurship and Sustainability Issues, 5(4). 780-794. http://doi.org/10.9770/jesi.2018.5.4(6) 